\title{
Clinical and cost-effectiveness of physiotherapy interventions following total knee replacement: a systematic review and meta-analysis
}

\author{
F. Fatoye ${ }^{1}$ (D) G. Yeowell ${ }^{1} \cdot$ J. M. Wright ${ }^{1} \cdot$ T. Gebrye $^{1}$
}

Received: 17 August 2020 / Accepted: 7 January 2021 / Published online: 7 February 2021

(c) The Author(s) 2021

\begin{abstract}
Purpose Osteoarthritis is the single most common cause of pain and disability in older adults. This review addresses the question of the clinical effectiveness and cost-effectiveness of physiotherapy interventions following total knee replacement (TKR).

Methods A systematic review was conducted according to the Preferred Reporting Items for Systematic Reviews and MetaAnalyses. MEDLINE, CINAHL, AMED, DARE, HTA and NHS EED databases were searched from inception to 02 May 2020. Search terms related to the clinical and cost-effectiveness of physiotherapy interventions were used. Studies meeting the inclusion criteria were identified and key data were extracted. Random effect meta-analysis was conducted for pain, physical function and range of motion (ROM).

Results In total, 1467 studies were identified. Of these, 26 studies were included; methodological quality of most studies was adequate. Physiotherapy interventions were more effective than control for function, SMD - 0.166 [95\% Confidence Interval (CI) -0.420 to 0.088.] and ROM, SMD - 0.219 [95\% CI - 0.465 to 0.028 ] for a follow-up of 2 or 3 months. Patients in the intervention group showed improvement in pain at 12-13 weeks, SMD -0.175 [95\% CI -0.416 to 0.067 ]. No evidence on the pooled estimate of cost-effectiveness of physiotherapy interventions was found.

Conclusions This is the first systematic review and meta-analysis that has examined the clinical and cost-effectiveness of physiotherapy interventions following TKR. The findings of this review suggest that physiotherapy interventions were effective for improving physical function, ROM and pain in a short-term follow-up following TKR. Insufficient evidence exists to establish the benefit of physiotherapy in the long term for patient with TKR. Further study should examine the long-term effectiveness and cost-effectiveness of physiotherapy interventions.
\end{abstract}

Keywords Cost-effectiveness analysis · Total knee replacement $\cdot$ Physiotherapy $\cdot$ Systematic review

\section{Introduction}

Osteoarthritis (OA) is a slowly progressive musculoskeletal disorder where the knee is the most common joint affected [1]. It is a major public health problem due to its prevalence, physical disability and high economic burden. The prevalence of knee OA was highest in high-income Asian Pacific regions such as Japan and South Korea [2]. Moreover, the

\section{F. Fatoye}

f.fatoye@mmu.ac.uk

1 Department of Health Professions, Faculty of Health, Psychology, and Social Care, Manchester Metropolitan University, Brooks Building, 53 Bonsall Street, Manchester M15 6GX, UK prevalence of knee OA in people aged $\geq 45$ years was projected to increase from $13.8 \%$ in 2012 to $15.7 \%$ in 2032 [3]. $\mathrm{OA}$ of the knee tends to be more prevalent in women [4]. Additional factors that contribute to the development of OA include knee injury, being overweight and obesity, old age, muscle weakness, repetitive use of joints, and bone density. The global age-standardised point prevalence and annual incidence rate of OA in 2017 were 3754.2 and 181.2 per 100,000 , respectively [5]. This is an increase of $9.3 \%$ for the point prevalence and $8.2 \%$ for the annual incidence rate from 1990. It is also highly likely to rise due to an increasing aging population and obesity [6].

It has been noted that $\mathrm{OA}$ is a leading indication for the use of pharmacological treatments [7]. The findings of a systematic review [8] suggested that the efficacy of all pharmacological 
treatments of knee OA significantly outperformed oral placebo for pain and function. However, when pharmacological and non-pharmacological treatments fail, surgery is recommended for patients with knee OA [9]. Total knee replacement (TKR) is a surgical procedure aimed at restoring function and resolving pain of knee OA [10]. In the majority of western healthcare system such as the United Kingdom between 150 and 250 per 100,000 of the population undergone TKR annually [11]. It is also estimated that a total of 3.48 million TKR per year will be performed by the year 2030 in the United States; however, approximately 1 out of 5 people that undergo TKR remain unsatisfied even with new technological advances such as knee kinematics [12].

Non-pharmacological interventions such as rehabilitation are an integral part of the overall recovery process following TKR as well as essential to improve clinical outcomes [13]. A systematic review and meta-analysis of physiotherapy exercise concluded that physiotherapy exercises were beneficial in the short term and provided small to moderate benefit for function, range of motion and quality of life (QoL) 3-4 months following TKR [13]. On the other hand, a non-significant difference was reported for physical function and knee range of motion between outpatient physiotherapy and home-based exercise regimes in patients following TKR [15]. In 2002, costs of arthroscopic surgery for $\mathrm{OA}$ and indirect costs from $\mathrm{OA}$ in the United Kingdom were estimated at $£ 1.34$ million and $£ 3.2$ billion, respectively [16]. Furthermore, older patients with OA in the United States of America spend annually on average $\$ 8601, \$ 2941$, and $\$ 4603$ for direct medical, drug and indirect work loss costs, respectively [7]. Given the range of physiotherapy interventions recommended for patients following TKR, it is important to consider their economic costs as well as clinical effectiveness in allocating healthcare resources [16]. The selection of a particular intervention depends not only on its clinical decisions but also its value for money (costeffectiveness). By comparing the costs and health effects of an intervention, cost-effectiveness analysis is important to investigate the extent to which it can be regarded as providing value for money [18].

Although several systematic reviews have been published $[14,15,19]$, they do not include recently published evidence nor consider the cost-effectiveness of physiotherapy interventions. The aim of this systematic review was, therefore, to: (1) update and synthesise the clinical effectiveness of physiotherapy interventions following TKR (2) summarize the costeffectiveness of physiotherapy interventions following TKR.

\section{Methods}

This systematic review used the Preferred Reporting Items for Systematic Reviews and Meta-Analysis (PRISMA) (Fig. 1), a technique that addresses the eligibility, data sources, selection of studies, data extraction and data analysis as a reporting guideline [20]. This review was registered on PROSPERO, with registration number, CRD: CRD42018096524.

\section{Information sources}

We searched MEDLINE, CINAHL, AMED, DARE, HTA and NHS EED databases from inception to 02 May 2020. All searches were limited to humans, English language, publication data and abstract available. We also hand searched from the references of key studies included in the review. Search results were screened for relevance according to the eligibility criteria outlined in Table 1.

The search and screening process was done by a team of systematic reviewers (FF, GY, JMW and TG) led by FF. We obtained full text for studies that seemed potentially relevant based on the title and abstracts. Two reviewers (FF and TG) independently assessed the full-text articles and selected studies that met the inclusion criteria. Reference lists of relevant review articles that met the inclusion criteria were also searched for articles. Any discrepancies between the reviewers were resolved by discussion with the other authors (GY and JMW).

\section{Study selection and quality assessment}

Two researchers (TG and FF) independently undertook the study quality assessment of the articles. Titles and abstracts that did not provide enough information regarding the eligibility criteria were considered for full-text evaluation. Fulltext articles were printed for further reading and to assess if they met the inclusion criteria. Any disagreements with regard to the study selection were resolved by discussion with the other authors (GY and JMW). The methodological quality of the included clinical effectiveness studies was assessed based on a tool recommended by Maher and colleagues [21]. This tool is a Physiotherapy Evidence Database (PEDro) scale designed for rating methodological quality of randomised controlled trials. The following cut-off points were used to determine the level of quality of the studies: 9-10, excellent; 6-8, good; $4-5$, fair; and $<4$, poor. Studies with a total score of at least six points were considered to be of adequate quality [21]. To assess the quality of reporting of the included cost-effectiveness studies, we completed the Consolidated Health Economic Evaluation Reporting Standards (CHEERS) statement [22]. The CHEERS statement contains a 24-item checklist. A total score of 1 was assigned if they fulfilled the requirement of reporting for that Item completely, 0 for not reporting and 0.5 for partial reporting. The maximum score for an article that reported completely all information was 24 . Studies with a score $\geq 20$ 


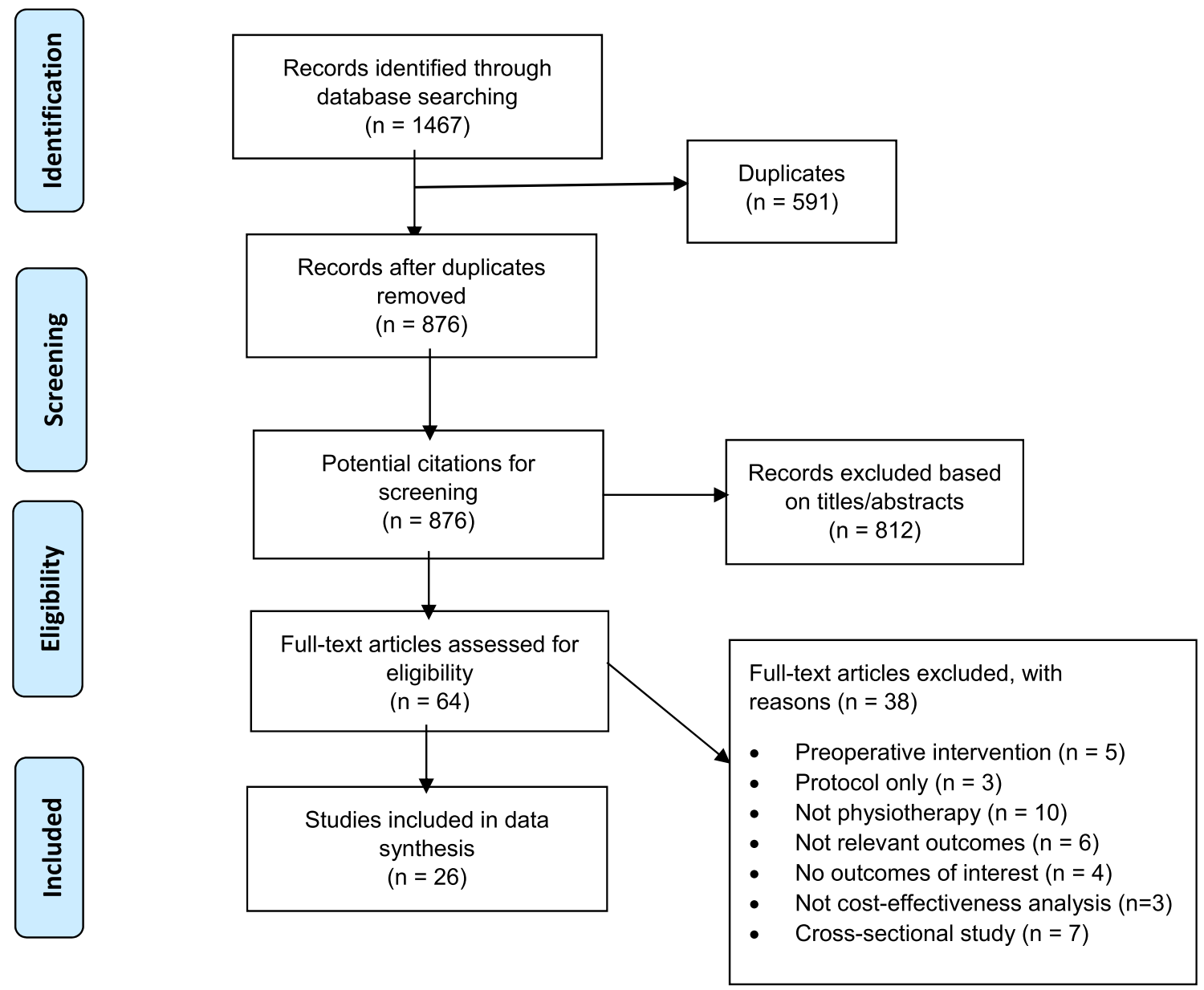

Fig. 1 Systematic review flow diagram

Table 1 The eligibility criteria

\begin{tabular}{ll}
\hline Inclusion & Exclusion \\
\hline Adults following TKR & Systematic reviews \\
Physiotherapy interventions & Conferences \\
$\begin{array}{l}\text { Standard care and no intervention were used as a comparator } \\
\begin{array}{l}\text { Pain, function, health-related quality of life (QoL), range of motion for } \\
\text { clinical effectiveness and cost per quality adjusted life year (QALY) for } \\
\text { cost-effectiveness }\end{array}\end{array}$ & $\begin{array}{l}\text { Abstracts } \\
\text { Randomised controlled trail for clinical effectiveness studies }\end{array}$ \\
\hline
\end{tabular}

out of total 24 were considered good quality whereas those less than 20 poor quality [22].

\section{Data extraction and analysis}

Two researchers (FF and TG) were involved in extracting the data from the included studies. For each of the included studies, the following data were extracted: author and date of the study, the location/country, type of patients, and the number of participants involved in the study were extracted.
The mean age, participants receiving the interventions and the control arms, length of follow-up, and the perspectives of the economic evaluation were extracted from each included study. Furthermore, data regarding results of the studies including pain, function, range of motion, health-related QoL were extracted for the clinical effectiveness studies. For the cost-effectiveness studies, data relating to cost per QALY or disability-adjusted life year (DALY) were extracted.

A descriptive synthesis and meta-analysis of the extracted data are presented. Meta-analysis was conducted using the 
Forest plot. Forest plot enables to illustrate results of selected studies graphically in a meaningful way. For the included clinical effectiveness and cost-effectiveness studies, relevant data including mean, standard deviation, and sample size wherever available were collected for quantitative synthesis. We used the Cohen $d$ as the effect size index. Effect size of each study was entered in to the Comprehensive Metaanalysis Software and were calculated for the intervention group relative to the comparison group. A random effect model was used to account for heterogeneity both withinand between studies. The type of interventions, the duration of the intervention and the source of the outcome measures were the main factors for estimating the pooled effect size of the included studies.

\section{Results}

The steps followed to select the studies for this review are presented in Fig. 1. The literature search strategy yielded 1467 records. Of these, after adjusting for duplicates 876 abstracts remained for consideration. After the titles and abstracts of the studies were screened, 64 full-text copies were obtained for further reading. Twenty-three studies met the inclusion criteria for the clinical effectiveness aspect of the review and 3 studies fulfilled the inclusion criteria for the cost-effectiveness. The methodological quality of the clinical effectiveness studies was assessed as adequate quality ( $>6$ point score) (Table 2 ). As indicated in Table 4, three of the included cost-effectiveness studies were of good quality, with scores ranging from 21 to 23 .

\section{Characteristics of the studies}

The studies included in this review evaluated the clinical effectiveness $(n=23)$ and cost-effectiveness $(n=3)$ of physiotherapy interventions using 2642 individuals following total knee replacement (Tables 3 and 4). The mean age of the patients that received physiotherapy interventions and control ranged from 64.1 to 74.6 and 65 to 75 , respectively. The duration of follow-up ranged from 1 week and 12 months. The included studies were conducted in UK $(n=8)$, USA $(n=2)$, Finland $(n=2)$, Canada $(n=3)$, Slovakia, Lithuania, India, Norway, Greece, Denmark, Italy, Netherlands, France, China, and Australia.
Table 2 Methodological quality of the included clinical effectiveness studies (PEDro scale)

\begin{tabular}{lccccccccccccc}
\hline Study & \multicolumn{1}{l}{ PEDro scale } & & & & & & & & \\
\cline { 2 - 11 } & 1 & 2 & 3 & 4 & 5 & 6 & 7 & 8 & 9 & 10 & 11 & Total \\
\hline Codine et al. [23] & 1 & 1 & 0 & 1 & 0 & 0 & 1 & 1 & 1 & 1 & 1 & 8 \\
Liu et al. [24] & 1 & 0 & 0 & 1 & 0 & 0 & 1 & 1 & 0 & 1 & 1 & 6 \\
Haas et al. [25] & 1 & 0 & 0 & 1 & 0 & 0 & 1 & 0 & 1 & 1 & 1 & 6 \\
Mitchell et al. [26] & 1 & 0 & 1 & 0 & 0 & 1 & 1 & 1 & 0 & 1 & 1 & 9 \\
Herbold et al. [27] & 1 & 0 & 0 & 1 & 0 & 0 & 1 & 1 & 0 & 1 & 1 & 6 \\
Hasubhai et al. [28] & 1 & 1 & 0 & 1 & 0 & 0 & 1 & 1 & 0 & 1 & 1 & 7 \\
Kauppila et al. [29] & 1 & 0 & 0 & 1 & 0 & 0 & 1 & 1 & 0 & 1 & 1 & 6 \\
Kramer et al. [30] & 1 & 1 & 0 & 1 & 0 & 0 & 1 & 1 & 0 & 1 & 1 & 7 \\
Artz et al. [31] & 1 & 1 & 0 & 1 & 0 & 0 & 1 & 1 & 0 & 1 & 1 & 7 \\
Frost et al. [32] & 1 & 1 & 1 & 1 & 1 & 1 & 1 & 1 & 0 & 1 & 1 & 10 \\
Mockford and Beverland [33] & 1 & 1 & 0 & 1 & 1 & 1 & 1 & 1 & 0 & 1 & 1 & 9 \\
Rajan et al. [34] & 1 & 1 & 0 & 1 & 0 & 0 & 1 & 1 & 0 & 1 & 1 & 7 \\
Bruun-Olsen et al. [35] & 1 & 1 & 1 & 1 & 1 & 1 & 1 & 1 & 1 & 1 & 1 & 11 \\
Evgeniadis et al. [36] & 1 & 1 & 1 & 1 & 1 & 1 & 0 & 1 & 0 & 1 & 1 & 8 \\
Madsen et al. [37] & 1 & 1 & 0 & 1 & 0 & 0 & 1 & 1 & 0 & 1 & 1 & 7 \\
Minns Lowe et al. [38] & 1 & 1 & 1 & 1 & 1 & 1 & 1 & 1 & 0 & 1 & 1 & 10 \\
Moffet et al. [39] & 1 & 1 & 0 & 1 & 1 & 1 & 1 & 1 & 0 & 1 & 1 & 9 \\
Monticone et al. [40] & 1 & 1 & 0 & 1 & 1 & 1 & 1 & 1 & 0 & 1 & 1 & 9 \\
Wang et al. [41] & 1 & 0 & 0 & 1 & 0 & 0 & 1 & 1 & 0 & 1 & 1 & 6 \\
Lenssen et al. [42] & 1 & 1 & 1 & 1 & 1 & 1 & 1 & 1 & 1 & 1 & 1 & 11 \\
Donec and Krisciunas [43] & 1 & 1 & 0 & 1 & 1 & 1 & 1 & 1 & 1 & 1 & 1 & 10 \\
Denis et al. [44] & 1 & 1 & 1 & 1 & 1 & 1 & 1 & 1 & 1 & 1 & 1 & 11 \\
Avramidis et al. [45] & 1 & 1 & 0 & 1 & 0 & 0 & 1 & 1 & 0 & 1 & 1 & 7 \\
\hline & & & & & & & & & & & \\
& 1 & 1 & 10 &
\end{tabular}

Note: 0 indicates no; 1 indicates yes 


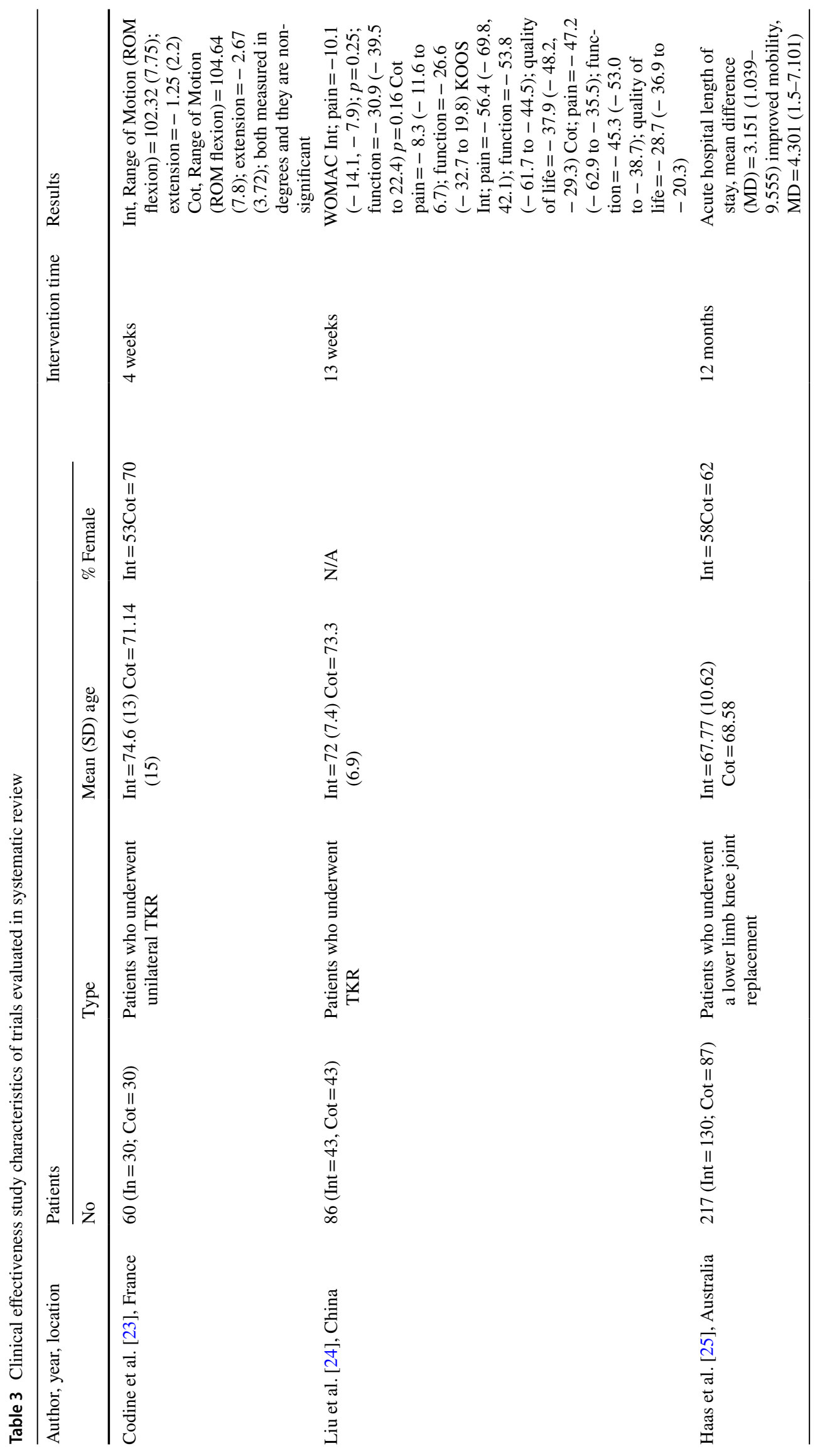




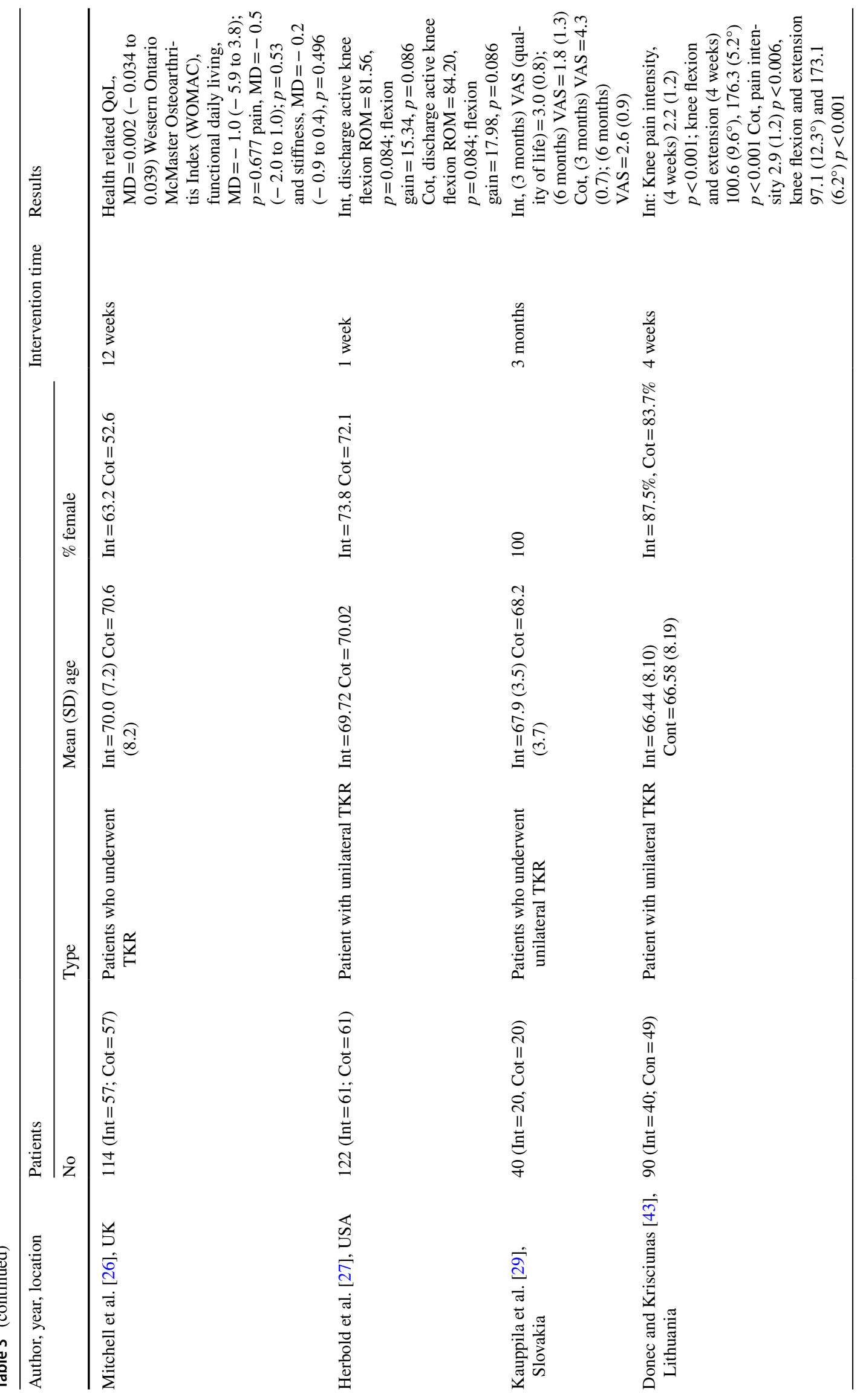




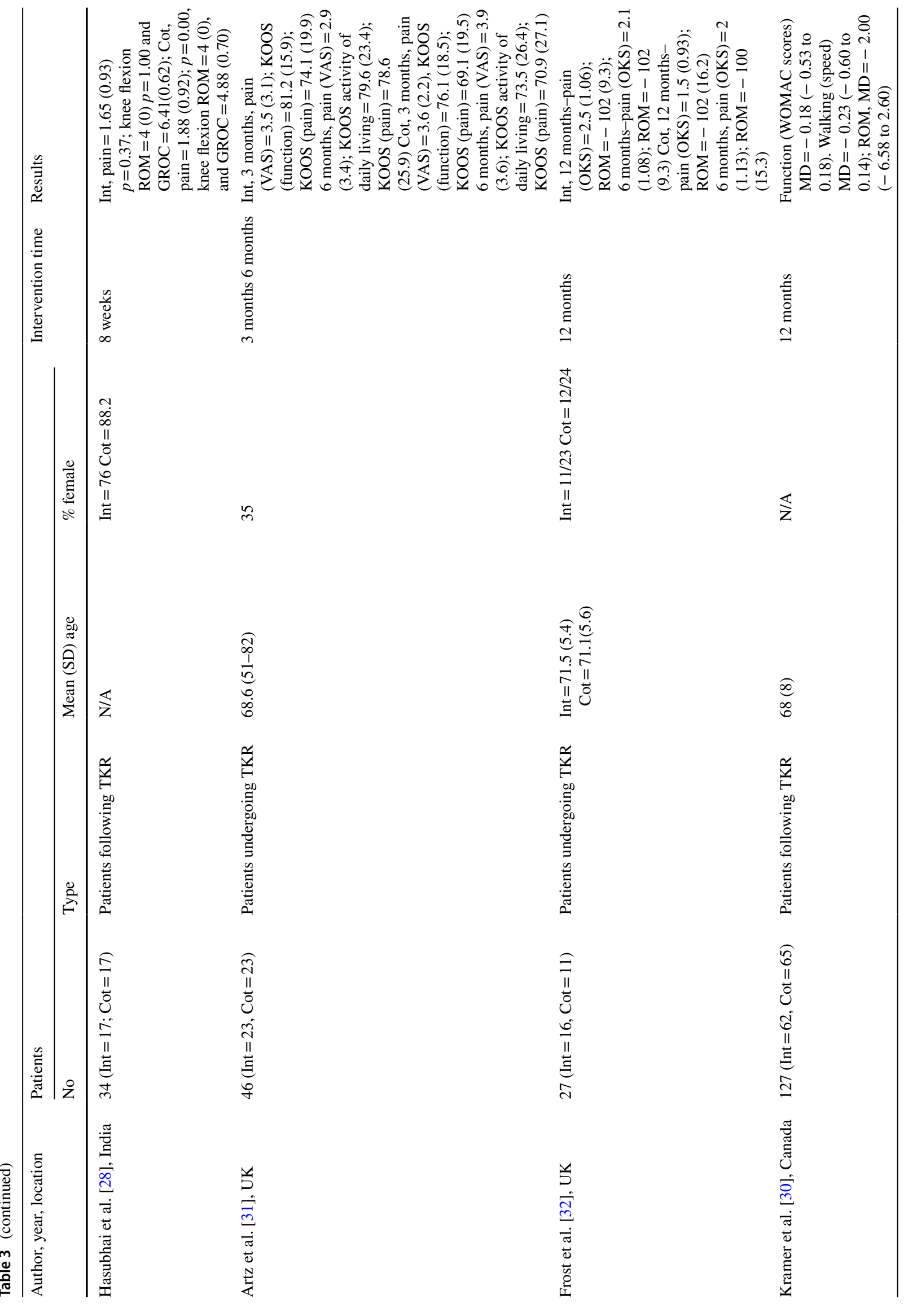




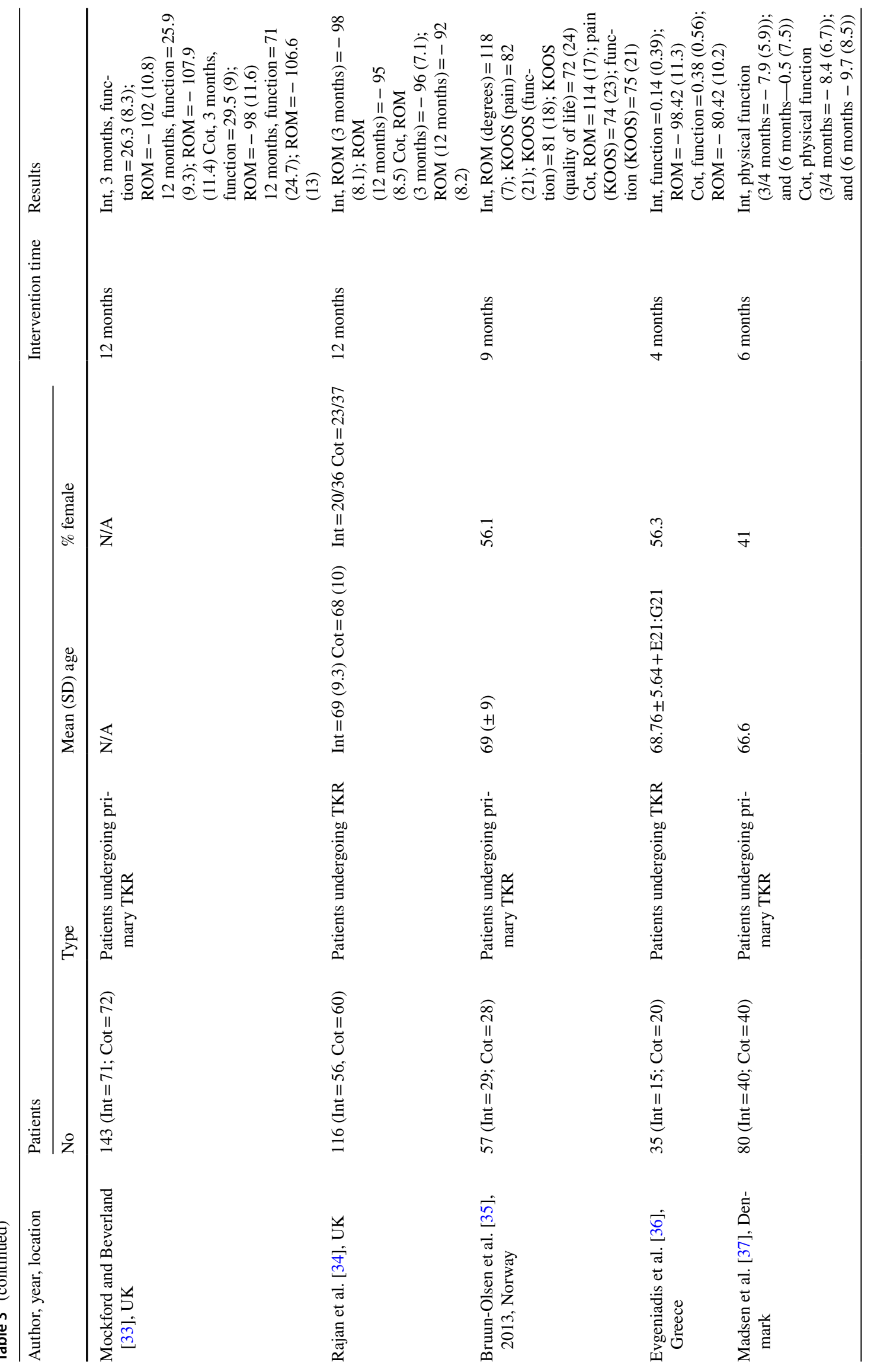




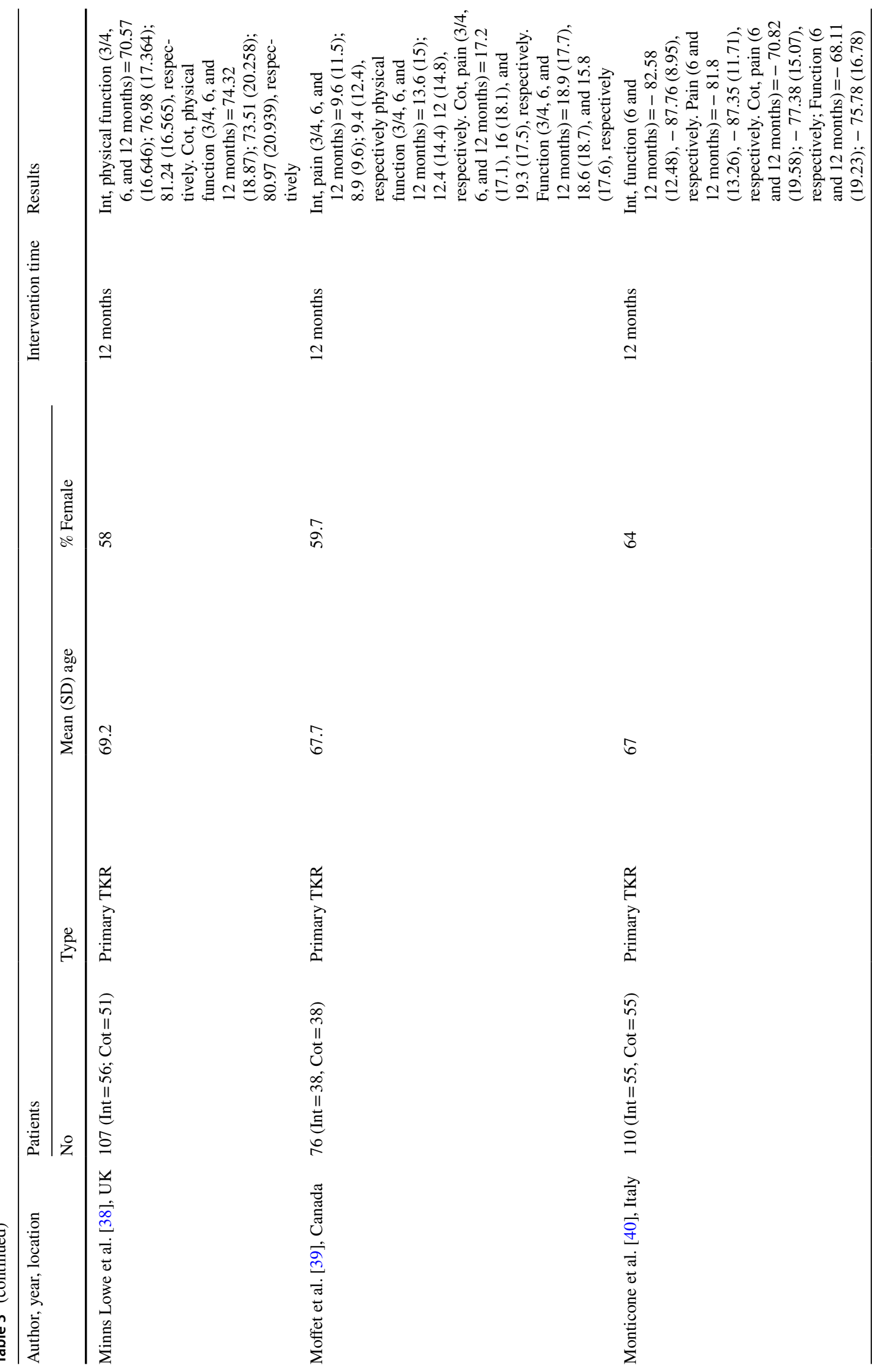




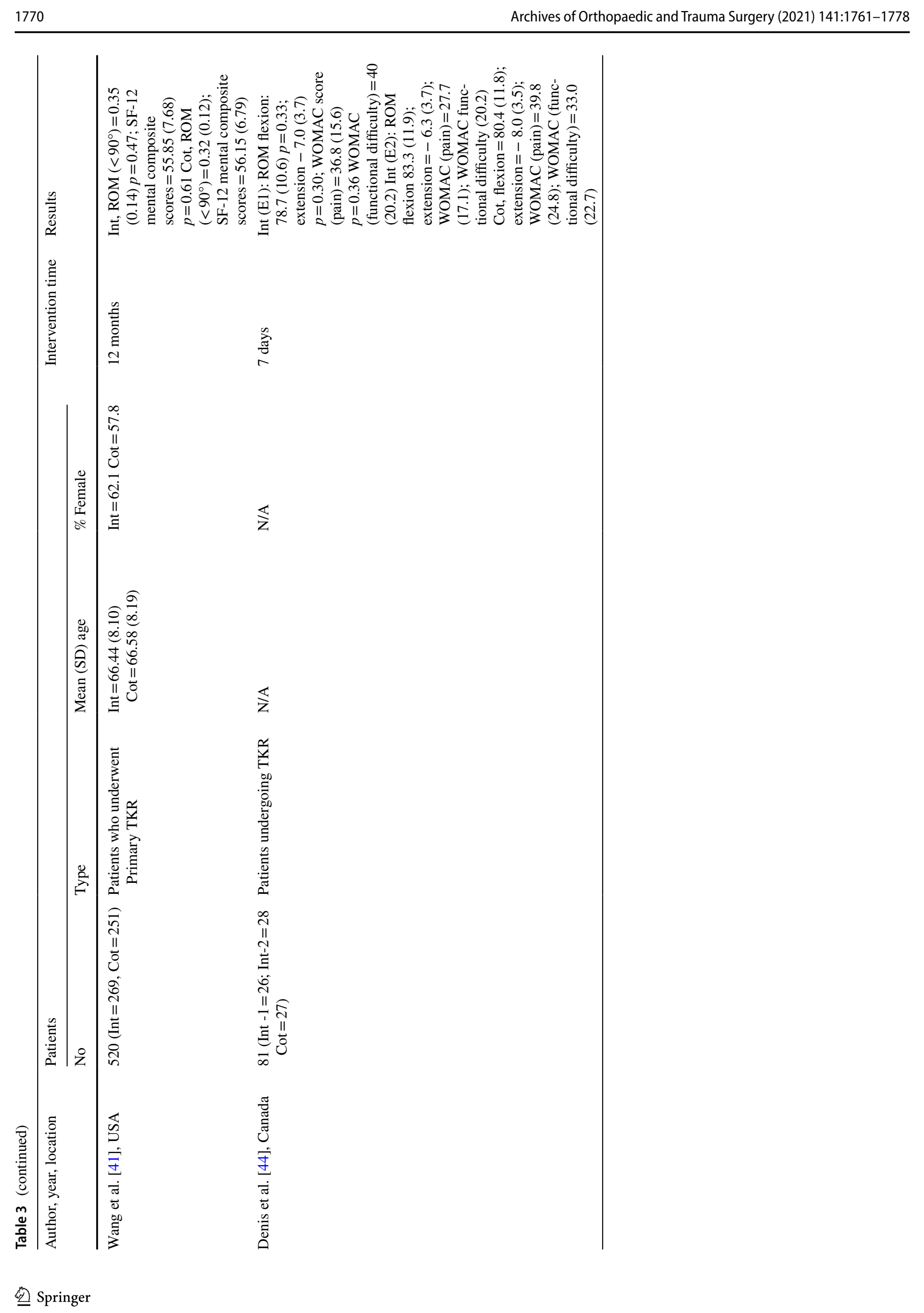




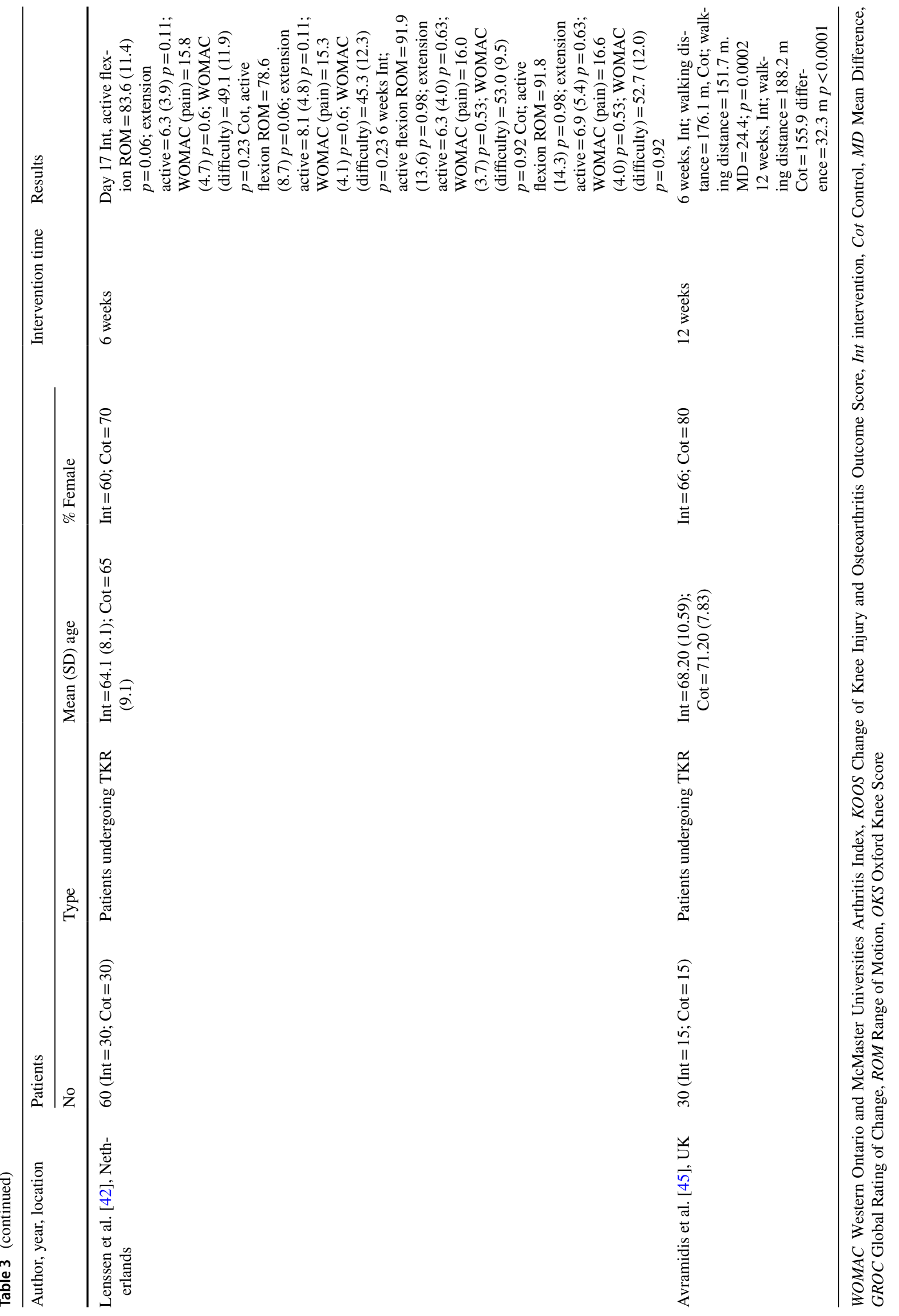




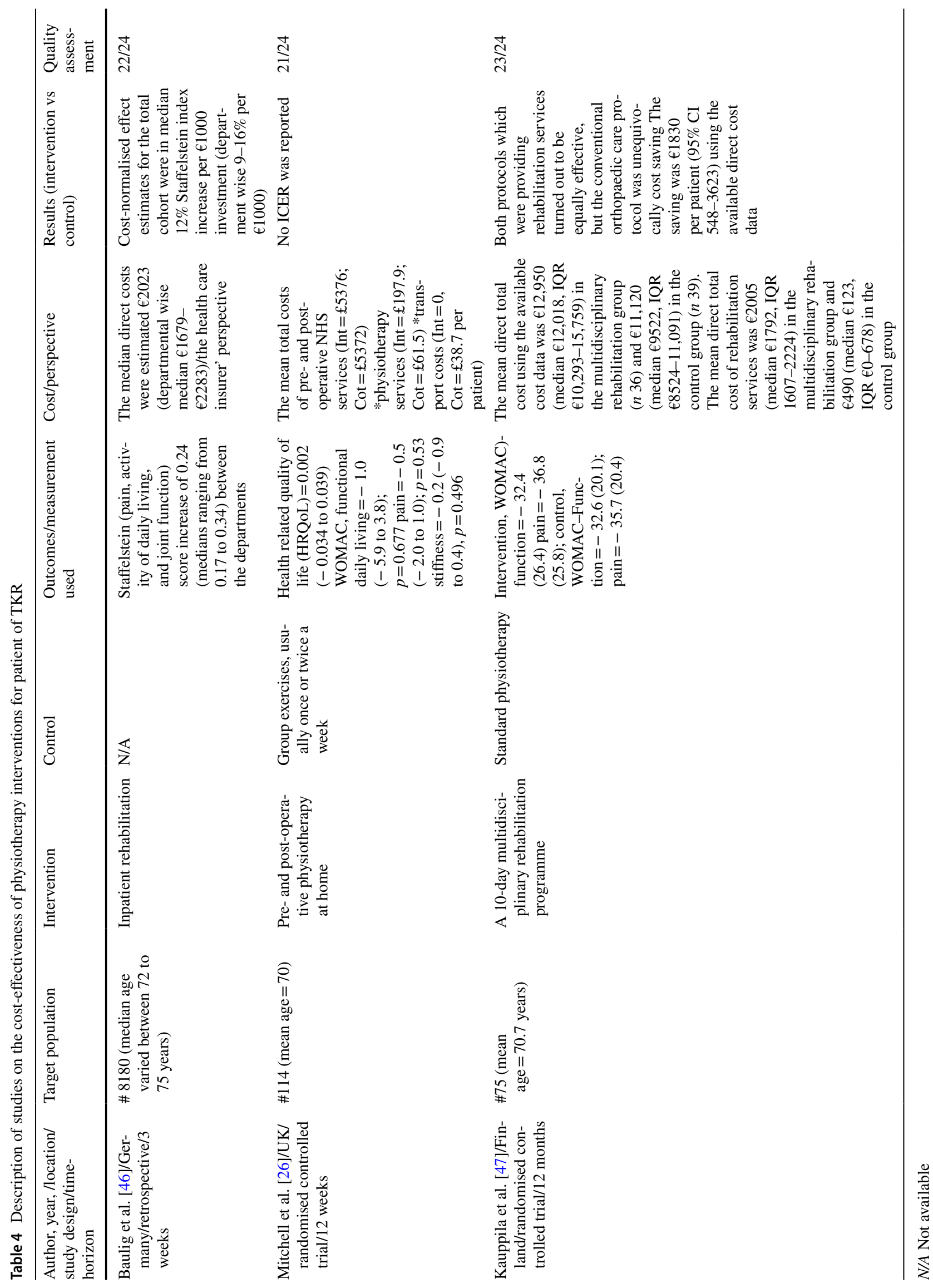




\section{Clinical effectiveness}

Twenty-three of the included studies in this review reported the clinical effectiveness of physiotherapy interventions including range of motion (ROM), pain, functional performance, mobility, hospital length of stay, and health-related QoL (Table 3). The clinical outcomes reported in the studies included in the review are summarised below.

\section{Range of motion}

Seven studies included in the review reported ROM [32-36, $41,42]$. Random effect of meta-analysis for ROM in individuals with TKR at 3-4 months (Fig. 2a) and 12 months (Fig. 2b) showed that physiotherapy interventions were statistically significant compared to control with standard mean difference (SMD) -0.219 [ -0.465 to 0.028$]$, and -0.315 [ -0.560 to 0.070$]$, respectively.

Some of the included studies reported the clinical effectiveness of physiotherapy interventions on knee flexion ROM only and knee extension ROM only. Data on knee flexion ROM were available in five studies with 366 patients $[23,27,28,42,43]$. The meta-analysis of the three studies $[23,42,43]$ indicated that patients that received physiotherapy interventions favoured the treatment group at 3 or 4 weeks, SMD - 0.055 [95\% CI -0.450 to 0.341] (Fig. 2c), however, this was not statistically significant.

Two of the included studies reported knee extension ROM on 150 patients $[23,43]$. The individual studies reported that participants receiving physiotherapy interventions had improved knee extension ROM at the end of the rehabilitation. On the other hand, the random effect meta-analysis for knee extension comparing physiotherapy interventions with control showed no significant difference, SMD 0.058 [95\% CI -0.943 to 1.058 ] (Fig. 3a).

\section{Patient reported pain}

Nine of the included studies reported the effect of physiotherapy interventions on knee pain scores [24, 26, 28, 29, $31,32,39,40,43]$. The random effect meta-analysis for pain at 12-13 weeks showed that physiotherapy interventions favoured the treatment group, SMD - 0.175 [95\% CI - 0.416 to 0.067] (Fig. 3b). Whereas, patients following TKR in the intervention group showed no benefit compared to control at 12 months (Fig. 3c).

\section{Function}

Ten studies reported functional activity in patients following physiotherapy interventions $[24,26,29,31-33,36,37$, $39,40]$. Random effect meta-analysis of four studies with 322 patients [24, 26, 31, 39] showed that functional activity of participants who received physiotherapy interventions improved their functional performance, SMD - 0.166 [- 0.420 to 0.088$]$ (Fig. 3d).

\section{Mobility}

Two studies reported the effect of electrical muscle simulation and acute weekend physiotherapy services on patient's mobility [25, 45]. Compared to no or minimal intervention those participants receiving the physiotherapy interventions in both studies showed a statistically significant improvement in mobility I the short term [45] and in the long term [25].

\section{Cost-effectiveness}

As indicated in Table 4, three studies on cost-effectiveness of physiotherapy interventions following TKR are included in this review [26, 46, 47]. Two studies [25, 46] were costeffectiveness studies alongside randomised controlled trials, whereas the remaining one study was a retrospective cohort study [46]. All the studies included in this part of costeffectiveness review considered direct costs from healthcare system and individual patient perspective. Two of the included studies reported that physiotherapy interventions for TKR were more expensive than the control and were not cost-effective [26,47]. The intervention arm of one of the included studies contained a preoperative group exercise programme on the surgical ward, and guided subsequent exercise program at a 2 month outpatient control visit to an orthopaedic surgeon [26]. Likewise, the second [47] and third [46] study included in the review involved individual treatments such as preoperative visits and up to six postdischarge visits and rehabilitation, respectively.

\section{Discussion}

To our knowledge, this is the first systematic review and meta-analysis that has examined the clinical and cost-effectiveness of physiotherapy interventions following TKR. The methodological quality of the included clinical effectiveness studies was assessed as adequate. Results of this meta-analysis of randomised controlled trials suggest that physiotherapy interventions improved the health status of the patients in terms of function, ROM, pain and mobility following TKR in a short term. With regards to the costeffectiveness of physiotherapy interventions for patients following TKR, the findings of the current review indicate that it is unlikely to be cost saving from the health system perspective. The included cost-effectiveness studies demonstrated that home physiotherapy, and a multidisciplinary rehabilitation programme were clinically effective; however, 


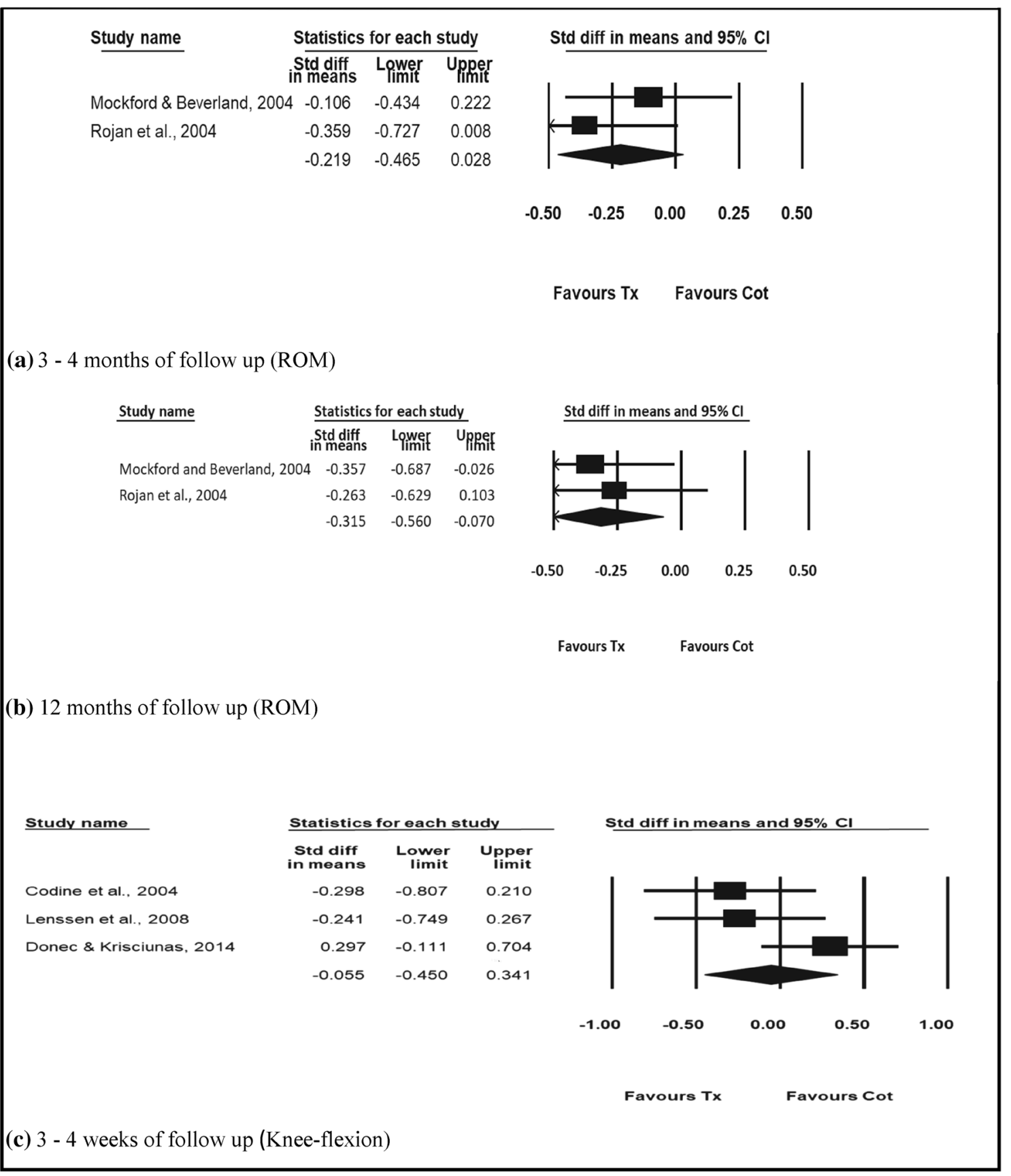

Tx $=$ Intervention, $\operatorname{Cot}=$ Control

Fig. 2 Physiotherapy exercise compared with control. a 3-4 months of follow-up (ROM). b 12 months of follow-up (ROM). c 3-4 weeks of follow-up (Knee-flexion). Tx Intervention, Cot Control

they were resource intensive in terms of healthcare resources compared to the control.

Physiotherapy interventions improved knee flexion ROM in patients after undergoing TKR compared to a control. Patients in the intervention groups were provided with continuous passive motion for 2 consecutive hours twice daily [42], Kinesio Taping that helped them to achieve mechanical correction [43] and training sub maximally using eccentric isokinetic strengthening [23]. On the other hand, the random effect meta-analysis for knee extension ROM showed no statistical difference between the intervention and control groups [23, 43].

In relation to patient reported pain, we found two different findings depending on the duration of follow-up of patients. Patients in the intervention group showed a reduction in pain, whereas no statistical difference was found 


\begin{tabular}{lccc} 
Study name & \multicolumn{3}{c}{ Statistics for each study } \\
\cline { 2 - 4 } & Std diff & Lower & Upper \\
in & 0.556 & 0.143 & 0.969 \\
Donec \& Krisciunas, 2014 & 0.556 & -0.978 & 0.048 \\
Codine et al., 2004 & -0.465 & -045 \\
& 0.058 & -0.943 & 1.058
\end{tabular}

(a) 3 - 4 weeks of follow up (Knee-extension)
Std diff in means and $95 \% \mathrm{CI}$

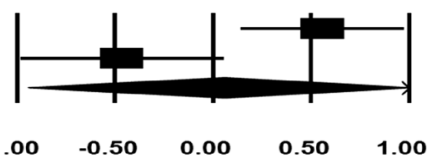

Favours Tx Favours Cot

\begin{tabular}{|c|c|c|c|}
\hline \multirow[t]{2}{*}{ Study name } & \multicolumn{3}{|c|}{ Statistics for each study } \\
\hline & intd diff & Lpwer & Upper \\
\hline Michell et al., 2005 & 0.025 & -0.342 & 0.392 \\
\hline Liu et al., 2018 & -0.198 & -0.622 & 0.225 \\
\hline Artz et al., 2017 & -0.037 & -0.615 & 0. \\
\hline Moffet et al., 2004 & -0.520 & -0.975 & -0.066 \\
\hline & -0.175 & -0.416 & 0.067 \\
\hline
\end{tabular}

(b) 12 - 13 weeks of follow up (Pain)
Study name

Kauppila et al., 2011 Monticone et al., 2013 Moffet et al., 2004
Statistics for each study intd diff means

5.401

$-0.189$

1.698 Lower
limit
-0.501
4.595 $-0.640$ $-1.052$
Std diff in means and $95 \% \mathrm{Cl}$

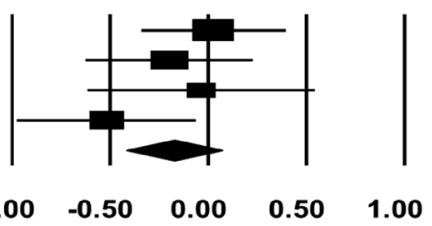

Favours Tx Favours Cot
Std diff in means and $95 \% \mathrm{Cl}$

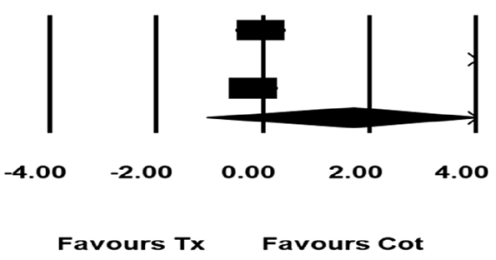

(c) 12 months of follow up (Pain)

\begin{tabular}{lccc} 
Study name & \multicolumn{3}{c}{ Statistics for each study } \\
intdd diff & Liwer & Upper \\
Artz et al., 2017 & 0.296 & -0.285 & 0.877 \\
Mitchell et al., 2005 & -0.106 & -0.473 & 0.262 \\
Liu et al., 2018 & -0.336 & -0.762 & 0.090 \\
Moffet et al., 2004 & -0.370 & -0.823 & 0.083 \\
& -0.166 & -0.420 & 0.088
\end{tabular}

Std diff in means and $95 \% \mathrm{Cl}$

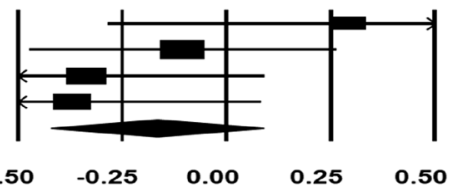

Favours Tx Favours Cot

(d) 12 - 13 weeks of follow up (Function)

$\mathrm{Tx}=$ Intervention, $\mathrm{Cot}=$ Control

Fig. 3 Physiotherapy exercise compared with control. a 3-4 weeks of follow-up (Knee-extension). b 12-13 weeks of follow-up (Pain). c 12 months of follow-up (Pain). d 12-13 weeks of follow-up (Function). Tx Intervention, Cot Control

between the intervention and control group was shown at 12 months. Similarly, compared to the control the metaanalysis of randomised controlled trials showed that patients in the intervention group improved functional activity and ROM. The clinical effectiveness results from our meta-analysis is consistent with the previous reviews of physiotherapy 
exercise after TKR $[14,19]$. These two reviews [14, 19] indicated that physiotherapy exercise resulted in improvements in physical function, ROM, and quality of life in short term. A previous review [14] has suggested that physiotherapy following TKR was not beneficial in the longer term.

The strengths and limitations of this review and metaanalysis should be considered. To provide reliable results, a rigorous appraisal of the evidence such as a prospective protocol, quality control of data and defined outcomes were considered. The present analysis included several studies involving approximately $30-520$ patients, which directly affected the pooled estimate of the clinical effectiveness of physiotherapy interventions.

One of the limitations of the study was that the definition of physiotherapy in the literature remains very broad. As a result, the studies identified in this review contained different forms of physiotherapy interventions that might have affected positively or negatively to the evidence provided in this review. Second, results of trials with negative findings may not have been published. Third, although this study provides valuable information on the cost-effectiveness of physiotherapy interventions, aggregation of evidence is limited due to heterogeneity in terms of study design, economic perspective, outcomes measures and the cost categories included. Furthermore, this review only considered studies published with English language which may have limited its generalisability. Finally, due to the variation of outcomes measures and time of follow-up, it was not possible to combine studies on health-related QoL and mobility to reach meaningful conclusions. Overall, given that physiotherapy interventions are associated with improved knee flexion ROM, knee extension ROM, pain, function and ROM in a short term and ROM at 12 months. Thus, the findings suggest physiotherapy can be considered to be clinically effective for patients following TKR.

\section{Conclusions}

The findings of this meta-analysis suggest that pain and function showed improvement in the short term with physiotherapy interventions following TKR. Moreover, the random effect of meta-analysis for ROM at 12 months showed that physiotherapy was beneficial compared to control. On the other hand, in the long-term patients reported no improvement in pain with physiotherapy interventions. Moreover, the results indicated that physiotherapy interventions for patients with TKR were neither cost-effective nor cost saving from health system perspective. Due to the nature of the evidence, particularly the uncertainty and small number of studies on the clinical effectiveness and cost-effectiveness, future studies should to properly monitor adherence to physiotherapy technique and provide high quality cost data. As evidence is continuing to emerge on the clinical and costeffectiveness of physiotherapy, we recommend that our findings are periodically reviewed and revised.

Author contributions All authors participated in the design, analysing the data, and interpreting the results of the work. FF, GY, JMW and TG wrote and critically revised the paper. All authors approved the final version of this manuscript.

Funding This research received no specific grant from any funding agency in the public, commercial, or not-for-profit sectors.

\section{Compliance with ethical standards}

Conflict of interest The authors have no conflict of interests to declare.

Ethical approval The study is a systematic review. For this study, ethical approval was not required.

Open Access This article is licensed under a Creative Commons Attribution 4.0 International License, which permits use, sharing, adaptation, distribution and reproduction in any medium or format, as long as you give appropriate credit to the original author(s) and the source, provide a link to the Creative Commons licence, and indicate if changes were made. The images or other third party material in this article are included in the article's Creative Commons licence, unless indicated otherwise in a credit line to the material. If material is not included in the article's Creative Commons licence and your intended use is not permitted by statutory regulation or exceeds the permitted use, you will need to obtain permission directly from the copyright holder. To view a copy of this licence, visit http://creativecommons.org/licenses/by/4.0/.

\section{References}

1. Vos T, Flaxman AD, Naghavi M, Lozano R, Michaud C, Ezzati M, Shibuya K, Salomon JA, Abdalla S, Aboyans V, Abraham J (2012) Years lived with disability (YLDs) for 1160 sequelae of 289 diseases and injuries 1990-2010: a systematic analysis for the global burden of disease study 2010. Lancet 380(9859):2163-2196

2. Cross M, Smith E, Hoy D, Nolte S, Ackerman I, Fransen M, Bridgett L, Williams S, Guillemin F, Hill CL, Laslett LL (2014) The global burden of hip and knee osteoarthritis: estimates from the global burden of disease 2010 study. Ann Rheum Dis 73(7):1323-1330

3. Turkiewicz A, Petersson IF, Björk J, Hawker G, Dahlberg LE, Lohmander LS, Englund M (2014) Current and future impact of osteoarthritis on health care: a population-based study with projections to year 2032. OsteoarthrCartil 22(11):1826-1832

4. Pereira D, Peleteiro B, Araujo J, Branco J, Santos RA, Ramos E (2011) The effect of osteoarthritis definition on prevalence and incidence estimates: a systematic review. OsteoarthrCartil 19(11):1270-1285

5. Safiri S, Kolahi AA, Hoy D, Smith E, Bettampadi D, Mansournia MA, Almasi-Hashiani A, Ashrafi-Asgarabad A, Moradi-Lakeh M, Qorbani M, Collins G (2019) Global, regional and national burden of rheumatoid arthritis 1990-2017: a systematic analysis of the global burden of disease study 2017. Ann Rheum Dis 78(11):1463-1471 
6. Zhang Y, Jordan JM (2010) Epidemiology of osteoarthritis. ClinGeriatr Med 26(3):355-369

7. White AG, Birnbaum HG, Janagap C, Buteau S, Schein J (2008) Direct and indirect costs of pain therapy for osteoarthritis in an insured population in the United States. J Occup Environ Med 50(9):998-1005

8. Bannuru RR, Schmid CH, Kent DM, Vaysbrot EE, Wong JB, McAlindon TE (2015) Comparative effectiveness of pharmacologic interventions for knee osteoarthritis: a systematic review and network meta-analysis. Ann Intern Med 162(1):46-54

9. Rönn K, Reischl N, Gautier E, Jacobi M (2011) Current surgical treatment of knee osteoarthritis. Arthritis 2011:454873

10. Weinstein AM, Rome BN, Reichmann WM, Collins JE, Burbine SA, Thornhill TS, Wright J, Katz JN, Losina E (2013) Estimating the burden of total knee replacement in the United States. J Bone Joint Surg Am 95(5):385

11. OECD/European Union (2016) Hip and knee replacement in Health at a glance: Europe: state of health in the EU cycle. OECD Publishing, Paris

12. Kurtz S, Ong K, Lau E, Mowat F, Halpern M (2007) Projections of primary and revision hip and knee arthroplasty in the United States from 2005 to 2030. J Bone Joint Surg Am 89(4):780-785

13. Nguyen C, Lefevre-Colau MM, Poiraudeau S, Rannou F (2016) Rehabilitation (exercise and strength training) and osteoarthritis: a critical narrative review. Ann PhysRehabilit Med 59(3):190-195

14. Lowe CJ, Barker KL, Dewey M, Sackley CM (2007) Effectiveness of physiotherapy exercise after knee arthroplasty for osteoarthritis: systematic review and meta-analysis of randomised controlled trials. BMJ 335(7624):812

15. Florez-García M, García-Pérez F, Curbelo R, Pérez-Porta I, Nishishinya B, Lozano MP, Carmona L (2017) Efficacy and safety of home-based exercises versus individualized supervised outpatient physical therapy programs after total knee arthroplasty: a systematic review and meta-analysis. Knee Surg Sports TraumatolArthrosc 25(11):3340-3353

16. Drummond MF, Sculpher MJ, Claxton K, Stoddart GL, Torrance GW (2015) Methods for the economic evaluation of health care programmes. Oxford University Press, New York

17. Chen AG, Gupte C, Akhtar K, Smith P, Cobb J (2012) The global economic cost of osteoarthritis: how the UK compares. Arthritis 2012:698709

18. Garber AM, Phelps CE (1997) Economic foundations of costeffectiveness analysis. J Health Econ 16(1):1-31

19. Artz N, Elvers KT, Lowe CM, Sackley C, Jepson P, Beswick AD (2015) Effectiveness of physiotherapy exercise following total knee replacement: systematic review and meta-analysis. BMC MusculoskeletDisord 16(1):15

20. Moher D, Liberati A, Tetzlaff J, Altman DG (2009) Preferred reporting items for systematic reviews and meta-analyses: the PRISMA statement. Ann Intern Med 151(4):264-269

21. Maher CG, Sherrington C, Herbert RD, Moseley AM, Elkins M (2003) Reliability of the PEDro scale for rating quality of randomized controlled trials. PhysTher 83(8):713-721

22. Husereau D, Drummond M, Petrou S, Carswell C, Moher D, Greenberg D et al (2013) Consolidated health economic evaluation reporting standards (CHEERS) statement. Cost Eff ResourAlloc 11(1):6

23. Codine PH, Dellemme Y, Denis-Laroque F, Herisson CH (2004) The use of low velocity submaximal eccentric contractions of the hamstring for recovery of full extension after total knee replacement: a randomized controlled study. IsokinetExerc Sci 12(3):215-218

24. Liu SC, Hou ZL, Tang QX, Qiao XF, Yang JH, Ji QH (2018) Effect of knee joint function training on joint functional rehabilitation after knee replacement. Medicine 97(28):e11270
25. Haas R, O'Brien L, Bowles KA, Haines T (2018) Effectiveness of a weekend physiotherapy service on short-term outcomes following hip and knee joint replacement surgery: a quasi-experimental study. ClinRehabil 32(11):1493-1508

26. Mitchell C, Walker J, Walters S, Morgan AB, Binns T, Mathers $\mathrm{N}$ (2005) Costs and effectiveness of pre-and post-operative home physiotherapy for total knee replacement: randomized controlled trial. J EvalClinPract 11(3):283-292

27. Herbold JA, Bonistall K, Blackburn M (2012) Effectiveness of continuous passive motion in an inpatient rehabilitation hospital after total knee replacement: a matched cohort study. PM R 4(10):719-725

28. Hasubhai PZ, Bid Dibyendunarayan D, Thangamani RA (2017) Effectiveness of conventional physiotherapy along with continuous passive motion after total knee arthroplasty. Indian J Physiother Occup Ther 11(4):196

29. Kauppila AM, Kyllönen E, Ohtonen P, Hämäläinen M, Mikkonen P, Laine V, Siira P, Mäki-Heikkilä P, Sintonen H, Leppilahti J, Arokoski JP (2010) Multidisciplinary rehabilitation after primary total knee arthroplasty: a randomized controlled study of its effects on functional capacity and quality of life. ClinRehabil 24(5):398-411

30. Kramer JF, Speechley M, Bourne R, Rorabeck C, Vaz M (2003) Comparison of clinic- and home-based rehabilitation programs after total knee arthroplasty. ClinOrthopRelat Res 410:225-234

31. Artz N, Dixon S, Wylde V, Marques E, Beswick AD, Lenguerrand E, Blom AW, Gooberman-Hill R (2017) Comparison of groupbased outpatient physiotherapy with usual care after total knee replacement: a feasibility study for a randomized controlled trial. ClinRehabil 31(4):487-499

32. Frost H, Lamb SE, Robertson S (2002) A randomized controlled trial of exercise to improve mobility and function after elective knee arthroplasty. Feasibility, results and methodological difficulties. ClinRehabil 16(2):200-209

33. Mockford BJ, Beverland DE (2004) Does an outpatient physiotherapy regime improve the range of knee motion after total knee arthroplasty: a prospective study. OrthopProc 86:128-128

34. Rajan RA, Pack Y, Jackson H, Gillies C, Asirvatham R (2004) No need for outpatientphysiotherapy following total knee arthroplasty: a randomized trial of 120 patients. Acta OrthopScand 75(1):71-73

35. Bruun-Olsen V, Heiberg KE, Wahl AK, Mengshoel AM (2013) The immediate and long-term effects of a walking-skill program compared to usual physiotherapy care in patients who have undergone total knee arthroplasty (TKA): a randomized controlled trial. DisabilRehabil 35(23):2008-2015

36. Evgeniadis G, Beneka A, Malliou P, Mavromoustakos S, Godolias G (2008) Effects of pre-or postoperative therapeutic exercise on the quality of life, before and after total knee arthroplasty for osteoarthritis. J Back MusculoskeletRehabil 21(3):161-169

37. Madsen M, Larsen K, Kirkegard Madsen I, Soe H, Hansen TB (2013) Late groupbased rehabilitation has no advantages compared with supervised home-exercises after total knee arthroplasty. Dan Med J 60(4):A4607

38. Minns Lowe CJ, Barker KL, Holder R, Sackley CM (2012) Comparison of postdischarge physiotherapy versus usual care following primary total knee arthroplasty for osteoarthritis: an exploratory pilot randomized clinical trial. ClinRehabil 26(7):629-641

39. Moffet H, Collet J-P, Shapiro SH, Paradis G, Marquis F, Roy L (2004) Effectiveness of intensive rehabilitation on functional ability and quality of life after first total knee arthroplasty: a single-blind randomized controlled trial. Arch Phys Med Rehabil 85(4):546-556

40. Monticone M, Ferrante S, Rocca B, Salvaderi S, Fiorentini R, Restelli M, Foti C (2013) Home-based functional exercises aimed 
at managing kinesiophobia contribute to improving disability and quality of life of patients undergoing total knee arthroplasty: a randomized controlled trial. Arch Phys Med Rehabil 94(2):231-239

41. Wang WL, Rondon AJ, Tan TL, Wilsman J, Purtill JJ (2019) Self-directed home exercises vs outpatient physical therapy after total knee arthroplasty: value and outcomes following a protocol change. J Arthroplast 34(10):2388-2391

42. Lenssen TA, Van Steyn MJ, Crijns YH, Waltjé EM, Roox GM, Geesink RJ, Van Den Brandt PA, De Bie RA (2008) Effectiveness of prolonged use of continuous passive motion (CPM), as an adjunct to physiotherapy, after total knee arthroplasty. BMC MusculoskeletDisord 9(1):1-1

43. Donec V, Kriščiūnas A (2014) The effectiveness of kinesio taping $^{\circledR}$ after total knee replacement in early postoperative rehabilitation period A randomized controlled trial. Eur J PhysRehabil Med 50(4):363-371

44. Denis M, Moffet H, Caron F, Ouellet D, Paquet J, Nolet L (2006) Effectiveness of continuous passive motion and conventional physical therapy after total knee arthroplasty: a randomized clinical trial. PhysTher 86(2):174-185
45. Avramidis K, Strike PW, Taylor PN, Swain ID (2003) Effectiveness of electric stimulation of the vastus medialis muscle in the rehabilitation of patients after total knee arthroplasty. Arch Phys Med Rehabil 84(12):1850-1853

46. Baulig C, Grams M, Rohrig B, Linck-Eleftheriadis S, Krummenauer F (2015) Clinical outcome and cost effectiveness of inpatient rehabilitation after total hip and knee arthroplasty. A multi-centre cohort benchmarking study between nine rehabilitation departments in Rhineland-Palatinate (Western Germany). Eur J PhysRehabil Med 51(6):803-813

47. Kauppila AM, Sintonen H, Aronen P, Ohtonen P, Kyllönen E, Arokoski JP (2011) Economic evaluation of multidisciplinary rehabilitation after primary total knee arthroplasty based on a randomized controlled trial. Arthr Care Res 63(3):335-341

Publisher's Note Springer Nature remains neutral with regard to jurisdictional claims in published maps and institutional affiliations. 